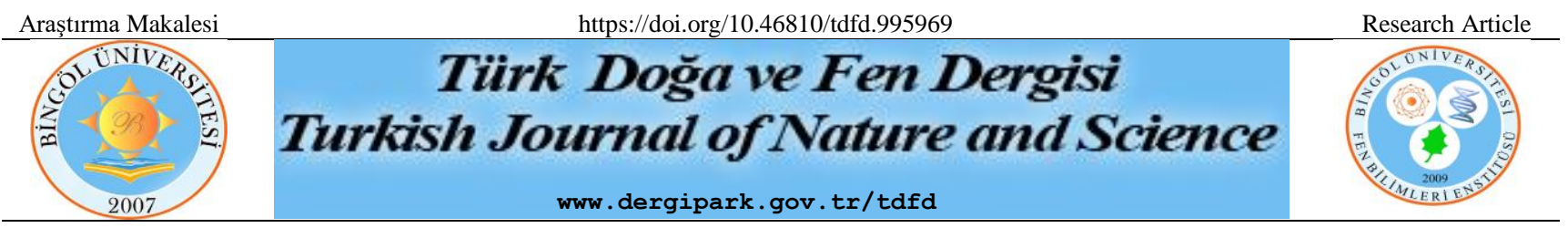

\title{
Bakırın Asidik Ortamdaki Korozyonuna Hurma (Phoenix dactylifera) Çekirdeğinin İnhibisyon Etkisinin İncelenmesi
}

\author{
Ece ALTUNBAŞ ŞAHIN ${ }^{1}$, Yeşim AYDIN DURSUN ${ }^{2}$, Mehmet TUNÇ ${ }^{3}$, İbrahim Halil GEÇİBESLER ${ }^{3}$, Ramazan \\ SOLMAZ ${ }^{3}$ \\ ${ }^{1}$ Bingöl Üniversitesi, Genç MYO, Sivil Savunma ve İtfaiyecilik Programı, 12000 Bingöl/Türkiye \\ ${ }^{2}$ Bingöl Üniversitesi, Fen Edebiyat Fakültesi Kimya Bölümü, 12000 Bingöl/Türkiye \\ ${ }^{3}$ Bingöl Üniversitesi, Sağlık Bilimleri Fakültesi, İş Sağlığı ve Güvenliği Bölümü, 12000, Bingöl/Türkiye \\ Ece ALTUNBAŞ ŞAHIN ORCID No: 0000-000232010487 \\ Yeşim AYDIN DURSUN ORCID ID: 0000-0003-2052-8817 \\ Mehmet TUNÇ ORCID ID:0000-0002-3757-2315 \\ İbrahim Halil GEÇİBESLER ORCID ID: 0000-0002-4473-2671 \\ Ramazan SOLMAZ ORCID ID: 0000-0002-9295-1203
}

*Sorumlu yazar: ealtunbassahin@gmail.com, easahin@bingol.edu.tr

(Alınış: 15.09.2021, Kabul: 13.10.2021, Online Yayınlanma: 31.12.2021)

Anahtar
Kelimeler
Korozyon
inhibitörleri,
Doğal atıklar,
Bakır,
Korozyon,
$\mathrm{H}_{2} \mathrm{SO}_{4}$
çözeltisi

\section{Anahtar}

Korozyon inhibitörleri,

Doğal atıklar,

Korozyon,

çözeltisi
Öz: İnhibitör kullanımı, metalik malzemeleri korozyondan korumak için tercih edilen en yaygın yöntemlerden bir tanesidir. Korozyon inhibitörü olarak organik maddeler yaygın olarak kullanılmaktadır. Bununla birlikte bu tür maddelerin yüksek maliyetleri ve toksik özellikleri kullanımlarını kısıtlar. Yapılan son çalışmalar, çevre dostu doğal ürünler ya da bu ürünlerden elde edilen atıkların korozyon inhibitörü olarak kullanılabildiklerini göstermektedir. Bu çalışmada, çevre dostu doğal bir atık olan hurma (phoenix dactylifera) çekirdeği ekstresinin (PDSE) bakırın 0,5 M $\mathrm{H}_{2} \mathrm{SO}_{4}$ çözeltisindeki korozyonuna inhibisyon etkisi araştırılmıştır. $\mathrm{Bu}$ amaçla, açık devre potansiyelinin zamanla değişimi $\left(E_{\text {ocp }} t\right)$, lineer polarizasyon direnci (LPR), elektrokimyasal impedans spektroskopisi (EIS) ve potansiyodinamik polarizasyon (PP) teknikleri kullanılmıştır. İnhibitörlü ortamda bekletilen bakırın yüzeyi SEM ve temas açısı kullanılarak karakterize edilmiştir. İnhibitör içeren ortamda bakırın yüzey yükü, sıfır yük potansiyeli (PZC) tekniği ile belirlenmiş ve bir adsorpsiyon mekanizması önerilmiştir. Sonuçlar, PDSE'nin 0,5 $\mathrm{M} \mathrm{H}_{2} \mathrm{SO}_{4}$ çözeltisinde bakırın korozyonunu yavaşlattı̆̆ını göstermiştir.

\section{Investigation of the Inhibition Effect of Palm (Phoenix dactylifera) Seed to the Corrosion of Copper}

\footnotetext{
Keywords Corrosion inhibitors, Natural wastes, Copper, Corrosion, $\mathrm{H}_{2} \mathrm{SO}_{4}$ solution
}

\begin{abstract}
The use of inhibitors is one of the most common methods preferred to protect metallic materials from corrosion. Organic substances as the corrosion inhibitors are widely used. However, high costs and toxic properties of organic substances restrict their use. Recent studies show that the wastes obtained from environmentally friendly natural products or products can be used as corrosion inhibitors. In this study, the inhibition of the effect of palm (phoenix dactylifera) seed (PDSE), which is an eco-friendly natural waste, on the corrosion of copper in $0.5 \mathrm{M} \mathrm{H}_{2} \mathrm{SO}_{4}$ solution was investigated. For this aim, the change of open circuit potential as a function of exposure time $\left(E_{\mathrm{ocp}}-t\right)$, linear polarization resistance (LPR), electrochemical impedance spectroscopy (EIS) and potentiodynamic polarization (PP) techniques were used. The surface of copper, which was exposed to the inhibited media was characterized by the SEM and contact angle measurements. The surface charge of copper in the inhibitor containing solution was determined by zero charge potential (PZC) technique and an adsorption mechanism was proposed. The results showed that PDSE slow the corrosion rate of copper in $0.5 \mathrm{M} \mathrm{H}_{2} \mathrm{SO}_{4}$ solution.
\end{abstract}




\section{GİRİş}

Bakır ve alaşımları yüksek termal iletkenlikleri, mekanik özellikleri, kolay ve düşük maliyette üretilmeleri gibi önemli özelliklerinden dolayı başta otomotiv ve elektronik endüstrisi olmak üzere birçok sektörde yaygın olarak kullanılmaktadırlar. Bununla birlikte en fazla ve en hızlı korozyona uğrayan yap1 malzemelerindendir. Bu durum, bakırın endüstriyel uygulamalarda kullanımını kısıtlamaktadır [1-5].

Korozyonu tanımlarken, metalik malzemenin çevresel etkilerle kimyasal ve elektrokimyasal olarak aşınması olarak ifade etmek doğru bir yaklaşım olacaktır. Metalik malzemeler kullanıldıkları ortamın da etkisi ile korozyona uğrarlar. Korozyon metalik malzemenin başta mekanik özellikleri olmak üzere birçok özelliğini değiștirerek kullanımını kısıtlarken ömrünü de azaltmaktadır [6-8].

Korozyon sadece metalik malzeme kaybı olarak düşünülmemelidir. Doğrudan veya dolaylı yollarla, başta endüstriyel yatırımlar olmak üzere birçok üretimin maliyetini de etkilediğini unutmamak gerekir. Yapılan çalışmalar dünyadaki korozyon kayıplarının ülkelere her y1l gayri safi milli hasılalarının yaklaşık \% $4-6$ 'sı arasında ilave bir yük yüklediğini göstermektedir. Türkiye için bu değerin \% 4,5 dolayında olduğu düşünülmektedir $[9,10]$.

İnhibitörler, korozif ortama az miktarlarda eklendiklerinde metalin korozyon hızını azaltan maddelerdir. Özellikle organik inhibitörler sanayide inhibitör uygulamalarında tercih edilmektedir. Bu tür maddeler, etkileşim halinde oldukları metalin yüzeyine adsorplanırlar [11]. Bu şekilde anodik ve katodik tepkimenin hızını azaltıp korozyonu yavaşlatabilirler. Özellikle yapısında karbonil ($\mathrm{C}=\mathrm{O})$, azo $(-\mathrm{N}=\mathrm{N}-)$, olefinik $(\mathrm{R}=\mathrm{R})$, azot, sülfür, fosfor ve oksijen bulunduran maddeler inhibitör uygulamalarında tercih edilmektedir. $\mathrm{Bu}$ yapıları bulunduran bileşiklerin metallerin korozyon hızını daha etkin bir şekilde düşürdüğü literatür çalışmaları ile tespit edilmiştir [12-14]. Bununla birlikte, metallerin korunması için organik inhibitör tercihi yapılırken, inhibitörün koruma etkinliğinin yanında çevreye olan toksik etkisi de göz önünde bulundurulmalıdır. Yüksek düzeyde koruma etkisi sağlayan bazı inhibitörler, toksik özelliklerinden dolayı çevreye büyük zararlar verebilmektedir [1214].

Bitkiler, bitki meyveleri, tohumlar, çeşitli kabuklar, bitki kökleri ve yaprakların ekstrelerinin inhibitör etkinlikleri birçok araştırmaya konu olmuştur [5,14]. Yapılan çalışmalar, bitki ekstrelerinin, inhibisyon etkinliği yüksek doğal olarak sentezlenmiş, amino asitler, organik asitler, alkaloitler, polifenoller ve tanenler açısından oldukça zengin kaynaklar olduğu belirlenmiştir [5,14,15].
Korozyon inhibitörü olarak sentetik inhibitörlerin kullanılması canlı sağlığı için tehdit oluşturduğundan, son zamanlarda birçok alternatif çevre dostu korozyon inhibitörü geliştirilmiştir. Doğal ürünler ve bu ürünlerin atıklarından elde edilen maddeler, ekonomik olmaları, üretimlerinin kolay olması ve çevre dostu olmaları nedeni ile korozyon inhibitörü uygulamalarında ön plana çıkmıştır [16-20]. Örneğin Rehan [21], hurma ve kına bitkilerinin yapraklarının sudaki ekstrelerinin, asidik ve alkali ortamda demir ve alüminyum için korozyon etkinliğini incelemiştir. Her iki tür içinde metal yüzeyinde inhibitörlerin, kimyasal inhibisyon temelli olduğu ve metal yüzeyine sıkı bir şekilde tutunduğunu belirtmişlerdir. $\mathrm{He}$ ve ark. [22], asidik ortamda, papaya yapraklarından elde ettikleri ekstrelerinin bakırın korozyon hızı üzerine etkisini araştırmışlardır. Deneysel sonuçlar, papaya yapraklarının bakırın asidik çözeltideki korozyonuna karma tip inhibitör olarak etki ettiğini göstermiştir. XPS sonuçlarına göre, $\mathrm{Cu}$ yüzeyinde $\mathrm{Cu}-\mathrm{S}$ bağı ve $\mathrm{Cu}-\mathrm{N}$ bağ 1 ile bir film oluşturmaktadır.

PDSE'nin yumuşak çeliğin asidik ortamdaki korozyon hızına etkisi [23] daha önce grubumuz tarafından çalıșılmıștır. Bununla birlikte; aynı maddenin bakır için inhibitör uygulamaları literatürde bulunmamaktadir.

$\mathrm{Bu}$ çalışmada, bakırın korozyonuna, çevre dostu doğal bir atık olan PDSE' nin inhibisyon etkisi $0,5 \mathrm{M}$ $\mathrm{H}_{2} \mathrm{SO}_{4}$ çözeltisinde araştırılmıştır. Açık devre potansiyelinin zamanla değişimi $\left(E_{\text {ocp }}-t\right)$, lineer polarizasyon direnci (LPR), elektrokimyasal impedans spektroskopisi (EIS) ve potansiyodinamik polarizasyon (PP) teknikleri bu amaçla kullanılmıştır. Bakırın yüzeyi, SEM ve temas açısı kullanılarak karakterize edilmiștir. İnhibitör içeren ortamda yüzey yükü sıfır yük potansiyeli (PZC) tekniği ile belirlenmiş ve adsorpsiyon mekanizması önerilmiştir.

\section{MATERYAL VE METOT}

\subsection{PDSE Ekstrelerinin Hazırlanması}

Çalışmada kullanılan hurma yerel marketlerden temin edilmiş ve kurutma işleminden önce kabuk, etli kısım ve çekirdek olarak ayrılmıştır. İnhibitör uygulamasında kullanılacak çekirdek, güneş 1 şığ almayacak şekilde baskısız kağıtlar üzerinde kurutulmuştur. Çekirdeğin tamamen kurutulmasından sonra, laboratuvar tipi bir değirmen yardımı ile ögürtme işlemi gerçekleştirilmiştir. Ögüutme işleminden sonra elde edilen ürün, farklı tanecik büyüklüklerine sahip eleklerden geçirilmiştir (1001400 mesh). Ekstraksiyon işlemi metanol:kloroform $(1: 1 ; \mathrm{v}: \mathrm{v})$ karışımında gerçekleştirilmiştir [23].

\subsection{Elektrotların Hazırlanmas}

Çalışma elektrotu olarak kullanılan, bileşimi bilinen (\% 99,9) bakır metali $0,283 \mathrm{~cm}^{2}$ yüzey alanına sahiptir ve silindirik çubuklardan yaklaşık $5 \mathrm{~cm}$ uzunluğunda kesilerek hazırlanmıştır. Bakır çubuklar 
kesildikten sonra, ölçüm yapılacak ucu açıkta kalacak şekilde polyester blok içerisinde gömülürken; diğer ucuna, iletkenliğin sağlanması için bakır tel geçirilmiştir [23]. Her ölçümden önce çalışma elektrotlarının yüzeyleri metal parlatıcı kullanılarak, farklı gritli (100-2000) zımpara kağıtları ile parlatılmıştır. 1 x $1 \mathrm{~cm}^{2}$ toplam yüzey alanına sahip Pt levha dan hazırlanan elektrot karşı elektrot olarak kullanılmıştır. Referans elektrot olarak ise ticari olarak temin edilen $\mathrm{Ag} / \mathrm{AgCl} \quad(3,0 \quad \mathrm{M} \quad \mathrm{KCl})$ kullanılmıştır.

\subsection{Elektrokimyasal Ölçümler}

Elektrokimyasal deneylerin tamamı üç elektrot tekniği yardımı ile CHI 6096E marka elektrokimyasal analizör kullanılarak yapılmıştır. Tüm deneyler, 298 ${ }^{\circ} \mathrm{K}$ 'de ve atmosfere açı koşullarda gerçekleştirilmiştir. Bakır elektrot, inhibitör içermeyen ve farklı derişimlerde (2000-100 ppm) inhibitör içeren $0,5 \mathrm{M} \mathrm{H}_{2} \mathrm{SO}_{4}$ çözeltisine daldırılmış ve açık devre potansiyelinin dengeye gelmesi için 1 saat bekletilmiştir. İnhibitörlü ve inhibitörsüz ortamlardaki açık devre potansiyellerinin dengeye geldiğini belirlemek için $E_{\text {ocp }} t$ eğrileri 1 saat boyunca kaydedilmiştir.

EIS ölçümleri, inhibitörlü ve inhibitörsüz ortamlarda $E_{\text {ocp }} t$ biter bitmez, sistemden okunan açık devre potansiyelinde gerçekleştirilmiştir. EIS eğrilerinden elde edilen sonuçlar ile inihbitörlü ve inhibitörsüz ortamlarda bakır elektrot için polarizasyon $\left(R_{\mathrm{p}}\right)$ değerleri hesaplanmıştır. Hesaplanan bu $R_{\mathrm{p}}$ değerlerinden PDSE’nin inhibisyon etkinliği (\% $\%$ ) Eşitlik 1'de belirtildiği gibi hesaplanmıştır [24];

$$
\% E=\left(\frac{R_{p}^{\prime}-R_{\mathrm{p}}}{R_{p}^{\prime}}\right) x 100
$$

Eşitlik 1'de verilen $R_{\mathrm{p}}$ değerleri ile inhibitörlü $\left(R_{\mathrm{p}}^{\prime}\right)$ ve inhibitörsüz $\left(R_{\mathrm{p}}\right)$ ortamlarda bakır elektrotun polarizasyon değerlerini ifade etmektedir.

EIS ölçümlerinin hemen ardından, aynı sistem kullanılarak LPR ölçümleri yapılmıştır. LPR ölçümleri açık devre potansiyelinden itibaren \pm 10 $\mathrm{mV}$ potansiyellerde, sabit tarama hızı (1,0 mVs-1) uygulanarak yapılmıştır. Elde edilen akım-potansiyel eğrilerinin eğiminden $R_{\mathrm{p}}$ değerleri inhibitörlü ve inhibitörsüz ortamlar için hesaplanmıştır. $R_{\mathrm{p}}$ değerlerinden bakırın farklı derişimlerde PDSE içeren asidik ortamda inhibisyon etkinliği (\% $\begin{array}{ll}\% & \text { E }\end{array}$ hesaplanmıştır [24].

PP ölçümleri, LPR ölçümleri hemen ardından, kullanılan sistem değiştirilmeden gerçekleştirilmiştir. PP ölçümleri, sistemden okunan açık devre potansiyellerinden daha katodik ve daha anodik potansiyellere doğru yapılmıştır $\left(1,0 \mathrm{mVs}^{-1}\right) \log i-E$ eğrilerinden korozyon akım yoğunluğu $\left(i_{\text {kor }}\right)$ değerleri hesaplanmıştır. Hesaplanan akım yoğunluğu yardımı ile de inhibitörlü ve inhibitör içermeyen asidik ortamlarda bakırın korozyon hızı belirlenmiştir. Elde edilen akım yoğunluğu değerlerinden inhibitör filmin etkinliği (\% E) Eşitlik 2 yardımı ile hesaplanmıştır [24].

$$
\% E=\left(\frac{i-i^{\prime}}{i}\right) \times 100
$$

Eşitlik 2'de verilen i' ve i sırası ile inhibitör içeren ve içermeyen asidik ortamlarda bakır elektrotun korozyon akım yoğunluğu değerlerini ifade etmektedir.

Bakırın yüzeyi, SEM, EDX, AFM ve temas açısı kullanılarak karakterize edilmiş ve inhibitör içeren ortamda yüzey yükü PZC tekniği ile belirlenmiştir.

\section{BULGULAR}

\subsection{Yüzey Analizleri}

Şekil 1a ve c ile b ve d'de, bakır elektrotun sırasıyla inhibitör içermeyen ve içeren ortamlardaki SEM ve AFM görüntüleri verilmiştir. Şekil 1'de görüldüğü gibi, inhibitör içeren ortamda, inhibitörsüz ortama göre oldukça farklı bir yüzey oluşmuştur. Buna göre, PDSE moleküllerinin asidik ortamda bakır yüzeyini kaplandı̆̆ı söylenebilir. Şekil 1e'de ise inhibitör içeren ortamda bakır elektrot için EDX sonuçları verilmiştir. Sonuçlar incelendiğinde, bakır yüzeyinde farklı oranlarda $\mathrm{S}, \mathrm{N}$ ve $\mathrm{P}$ elementleri olduğu görülmektedir. $\mathrm{Bu}$ durum, yüzeyde PDSE inhibitörünün varlığını kanıtlamaktadır [25].

Ayrıca, N, S ve P içeren birçok maddenin korozyon inhibitörü olarak kullanıldı̆̆ 1 göz önünde bulundurulduğunda [24], PSDE içinde asidik ortamda korozyon inhibitörü olarak etkin bir durum sergileyeceği düşünülebilir.

İnhibitör çalışmalarında metal yüzeyinin (film) hidrofobik/hidrofilik özelliklerini belirlemek için temas açısı ölçümleri kullanılır. İnhibitörlü ve inhibitörsüz ortamlarda elde edilen temas açısı verileri Şekil $1 \mathrm{f}$ ve g'de gösterilmiştir. Asidik ortama maruz kalan bakır için temas açısı 54,83' dir. Öte yandan, temas açısı, PDSE içeren asidik ortamda 1 saat boyunca inhibe edilmiş çözeltiye maruz kalan metal yüzeyde $75,305^{\circ}$ 'e yükselmiştir. Artan temas açısı değeri, bakır yüzeyine inhibitör moleküllerin adsorpsiyonu ile açıklanabilir ve bu durum yüzeyin hidrofobikliğini arttırabilir [26]. 

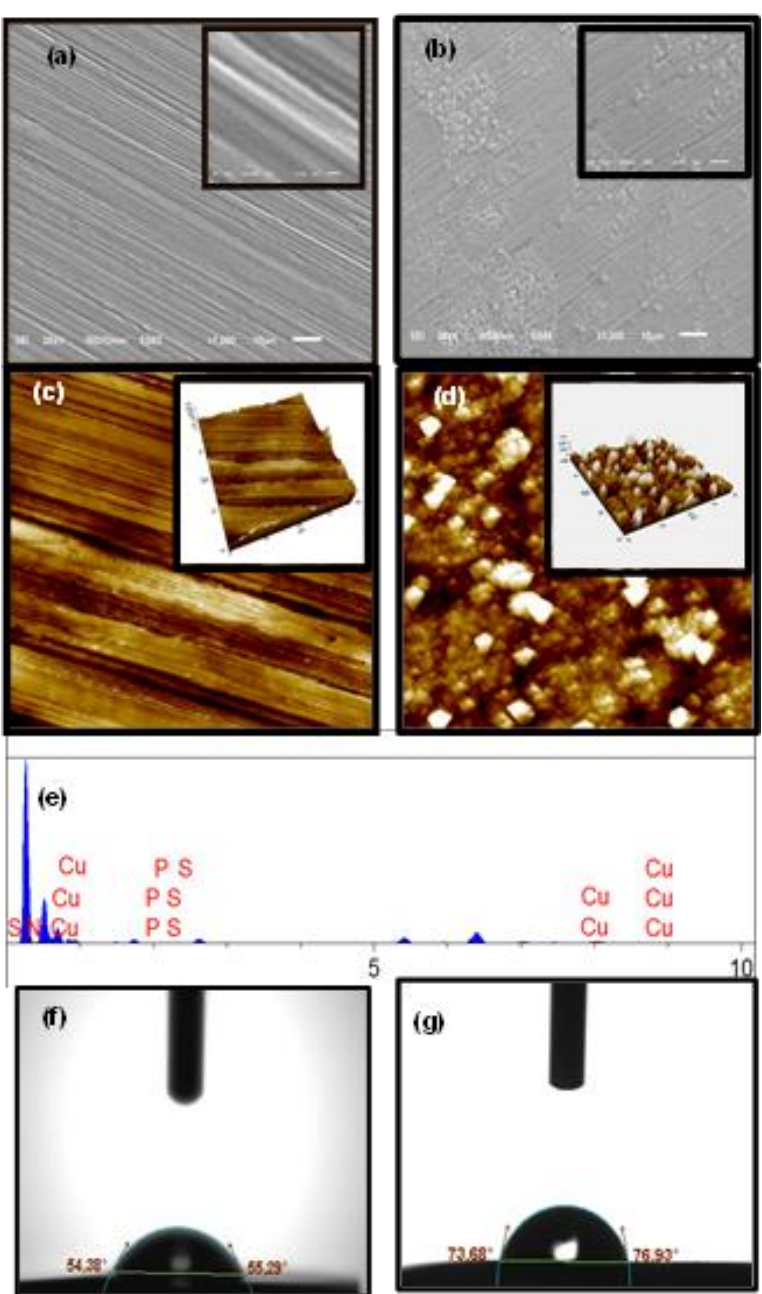

Şekil 1. Bakır elektrotun PDSE içermeyen (a,c,f), PDSE içeren (b,d,g) $0.5 \mathrm{M} \mathrm{H}_{2} \mathrm{SO}_{4}$ çözeltisinde SEM (a, b), AFM görüntüleri (c, d) ve temas açııı ölçümleri (f, g) ve PDSE içeren asidik ortamdaki EDX spektrumu

\subsection{Elektrokimyasal Analizler}

\subsubsection{Açı Devre Potansiyelinin Zamanla Değişimi}

Bakır elektrot inhibitör içermeyen ve farklı derişimlerde inhibitör içeren $0,5 \quad \mathrm{M} \quad \mathrm{H}_{2} \mathrm{SO}_{4}$ çözeltilerinde 1 saat boyunca aç1k devre potansiyelinin dengeye gelmesi için daldırılmıştır. Elde edilen açık devre potansiyelinin zamanla değişim $\left(E_{\mathrm{ocp}}-t\right)$ eğrileri Şekil 2 'de verilmiştir.

Şekil 2'de görüldüğü gibi inhibitör içermeyen ortamda, bakırın asidik ortamdaki açık devre potansiyeli negatif potansiyellere kaymaktadir. Asidik ortama PDSE inhibitörü eklendiğinde ise bakır için potansiyel değerlerinin azaldığ 1 ve inhibitör içermeyen ortama göre daha negatif potansiyellerde olduğu belirlenmiştir. $\mathrm{Bu}$ durum, 0,5 $\mathrm{M} \mathrm{\textrm {H } _ { 2 } \mathrm { SO } _ { 4 }}$ çözeltisinde PDSE inhibitörü varlığında, bakırın katodik reaksiyonu üzerindeki etkisinin anodik reaksiyona göre daha etkin olması ile açıklanabilir [26, 27].

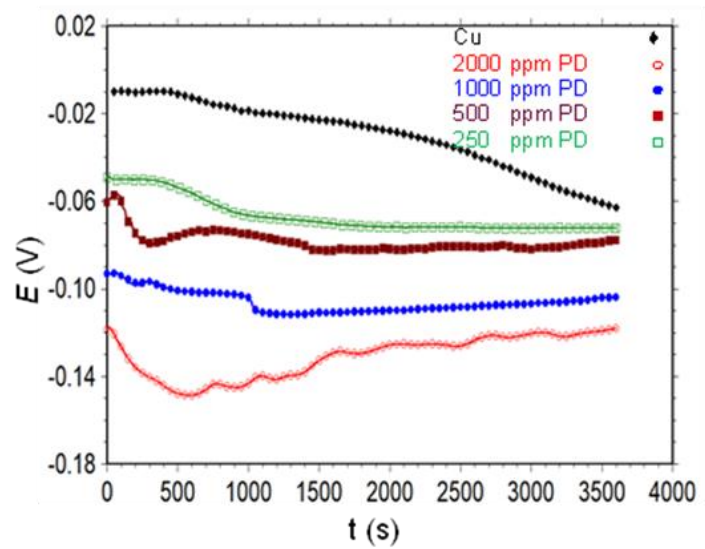

Şekil 2. Bakır elektrotun farklı derişimlerde PDSE içeren (2000 ppm: ○, 1000 ppm PD. •, 500 ppm PD: घ, 250 ppm PD: $\square) v e$ içemeyen $0,5 \mathrm{M} \mathrm{H}_{2} \mathrm{SO}_{4}$ çözeltilerde elde edilen $E_{\text {ocp }} t$ eğrileri

\subsubsection{Elektrokimyasal İmpedans Ĕ̆rileri}

Bakır için farklı derişimlerde (2000-100 ppm) PDSE içeren $0,5 \mathrm{M} \mathrm{H}_{2} \mathrm{SO}_{4}$ çözeltisinde 1 saat daldırma süresi sonunda elde edilen Nyquist eğrileri Şekil 3'te, bu eğrilerden elde edilen elektrokimyasal parametreler ise Tablo 1'de verilmiştir. Şekil 3'te verilen Nyqusit eğrileri incelendiğinde; inhibitör içeren ortamlarda, her derişim için eğrinin şekli değişmemekle birlikte inhibitör içermeyen ortamla kıyaslandığında direncin önemli ölçüde artığ1 görülmektedir. İnhibitör içeren ortamlarda $R_{\mathrm{p}}$ değerleri artan derişimle birlikte artmaktadır. Bakır için Nyquist eğrilerinden hesaplanan $R_{\mathrm{p}}$ değeri 77 ohm $\mathrm{cm}^{2}$ 'dir. En yüksek derişim için belirlenen $R_{\mathrm{p}}$ değeri $7395 \mathrm{ohm} \mathrm{cm}^{2}$, dir. Bu artış, inhibitörün metal yüzeyine adsorplanı koruyucu bir film oluşturduğunu göstermektedir [3, 4, 11]. Ayrıca Tablo 1'de görüldüğü gibi LPR ölçümlerinden elde edilen $R_{\mathrm{p}}$ değerleri, Nyquist eğrilerinden elde edilen değerler ile uyumludur.

Tablo 1. Bakır elektrotun $0,5 \quad \mathrm{M} \mathrm{H}_{2} \mathrm{SO}_{4}$ çözeltisi ve farklı derişimlerde PDSE içeren ortamlarda EIS ve LPR ölçümlerinden elde edilen korozyon parametreleri

\begin{tabular}{cccccc}
\hline & \multicolumn{3}{c}{ LIS } & LPR \\
& $\boldsymbol{C}(\mathbf{p p m})$ & $\boldsymbol{R}_{p} / \mathbf{\Omega} \mathbf{~ c m}^{\mathbf{2}}$ & $\boldsymbol{E} \%$ & $\boldsymbol{R}_{p^{*}} \mathbf{\Omega} \mathbf{~ c m}^{2}$ & $\boldsymbol{E} \%$ \\
\hline $\mathrm{Cu}$ & - & 77 & - & 77 & - \\
& 100 & 1919 & 96.0 & 1699 & 95,4 \\
& 250 & 1988 & 96,1 & 1792 & 95,7 \\
PDSE & 500 & 4473 & 98,3 & 3442 & 97,7 \\
& 1000 & 5580 & 98,6 & 3873 & 98,0 \\
& 2000 & 7395 & 98,9 & 5533 & 98,6 \\
\hline
\end{tabular}

Metal/çözelti ara yüzeyinde inhibitör moleküllerinin adsorpsiyonu, $R_{\mathrm{p}}$ değerlerini arttırmaktadır. $R_{\mathrm{p}}$ 'nin artması, bakırın korozyon hızının azaldığını göstermektedir [27]. 


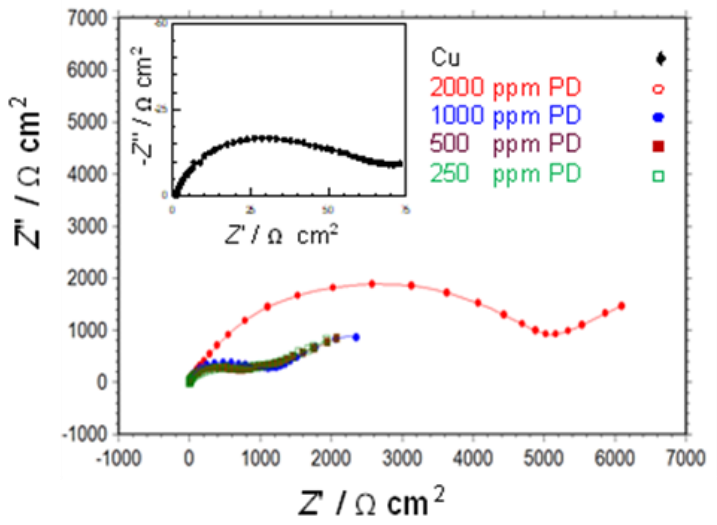

Şekil 3. Bakır elektrotların farklı derişimlere PDSE içeren 2000

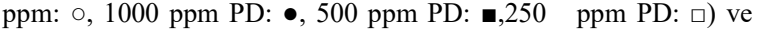
içemeyen $0,5 \mathrm{M} \mathrm{H}_{2} \mathrm{SO}_{4}$ çözeltilerinde elde edilen Nyquist eğrileri

\subsubsection{Yarı Logaritmik Akım-Potansiyel Eğrileri}

İnhibitör içermeyen ve farklı derişimlerde (2000 $100 \mathrm{ppm}$ ) PDSE içeren $0,5 \mathrm{M} \mathrm{H}_{2} \mathrm{SO}_{4}$ çözeltisinde bakırın elektrokimyasal davranışları yarı logaritmik akım potansiyel eğrilerinden faydalanarak belirlenmiştir. Elde edilen eğriler Şekil 4'te, bu eğrilerden hesaplanan korozyon hızı $\left(i_{\text {kor }}\right)$, korozyon potansiyeli $\left(E_{\mathrm{kor}}\right)$, korozyon hız $(\mathrm{KH})$ ve inhibisyon etkinliği (E\%) sonuçları Tablo 2'de verilmiştir. Bakırın, inhibitör içermeyen $0,5 \quad \mathrm{M} \quad \mathrm{H}_{2} \mathrm{SO}_{4}$ çözeltisinde belirlenen $E_{\text {kor }}$ değeri 0,020 V'dur. Aynı ortamda ve aynı koşullarda ortama farklı derişimler de inhibitör eklenmesi ile eğrilerinin karakteristiğinin değişmediği, bununla birlikte $E_{\text {kor }}$ değerlerinin daha negatif potansiyellere kaydığı gözlemlenmiştir. $E_{\mathrm{ko}} \mathrm{r}$ değerlerindeki bu kayma, artan inhibitör derişimi ile artarken, değerler -0,098V ile -0,069 V aralığındadır.

Tablo 2'den görüleceği gibi inhibitör içermeyen asidik ortamda bakır için $i_{\text {kor }}$ değeri $4,789 \mu \mathrm{A} \mathrm{cm} \mathrm{cm}^{-}$ ${ }^{2}$ dir. PDSE inhibitörünün varlığında ise $i_{\text {kor }}$ daha düşük değerlerdedir $\left(0,926-3,729 \mu \mathrm{Acm}^{-2}\right)$. Bu rakamsal verilerden de anlaşılacağı gibi, asidik ortama PDSE inhibitörünün farklı derişimlerde eklenmesi, anodik metal çözünmesi ve katodik bölgede hidrojen oluşum reaksiyonunu azaltmaktadır. Potansiyodinamik ölçümlerden belirlenen etkinlik değerleri \% 80,66 - 22,55 aralığında değişmektedir.

Tablo 2. Farklı derişimlerde PDSE içeren ve içermeyen 0,5 M $\mathrm{H}_{2} \mathrm{SO}_{4}$ çözeltilerde yarı logaritmik akım-potansiyel eğrilerinde elde edilen korozyon parametreleri

\begin{tabular}{|c|c|c|c|c|c|}
\hline & $\begin{array}{c}\mathrm{C} \\
(\mathbf{p p m})\end{array}$ & $\begin{array}{c}E_{\mathrm{kor}} \\
(\mathrm{V}, \mathbf{A g} / \mathbf{A g C l})\end{array}$ & 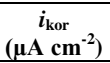 & $\begin{array}{c}\mathrm{KH} \\
\left(\mathrm{mm} \mathrm{yll}^{-1}\right)\end{array}$ & $E \%$ \\
\hline \multirow[t]{3}{*}{$\mathrm{Cu}$} & - & 0,020 & 4,789 & 196,1 & \\
\hline & 100 & $-0,069$ & 3,709 & 151,8 & 22,55 \\
\hline & 250 & $-0,067$ & 3,144 & 47,34 & 34,35 \\
\hline \multirow[t]{3}{*}{ PDSE } & 500 & $-0,070$ & 2,144 & 32,28 & 55,23 \\
\hline & 1000 & $-0,090$ & 1,068 & 16,08 & 77,70 \\
\hline & 2000 & $-0,098$ & 0,926 & 13,94 & 80,66 \\
\hline
\end{tabular}

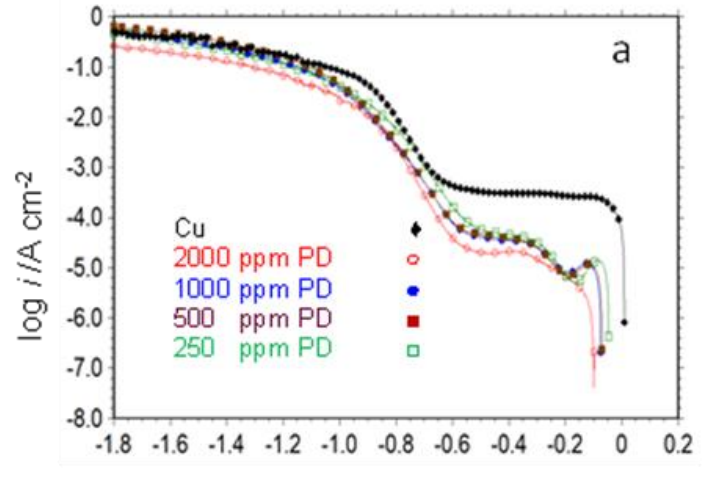

$E / V$

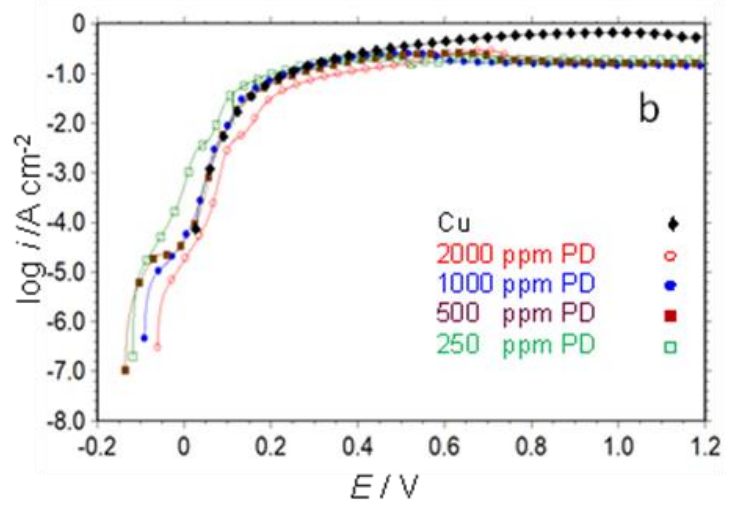

Şekil 4. Bakır elektrotun farklı derişimlerde PDSE içeren ve içemeyen 0,5 $\mathrm{M} \mathrm{H}_{2} \mathrm{SO}_{4}$ çözeltilerinde elde edilen katodik (a) ve anodik (b) akım-potansiyel eğrileri

\subsubsection{Adsorpsiyon İzotermi ve Yüzey Mekanizması}

Korozyon çalışmalarında, metal yüzeyi ve inhibitör molekülleri arasındaki etkileşimler adsorpsiyon izotermleri yardımıyla aydınlatılabilir [27]. Metal/çözelti ara yüzeyindeki adsorpsiyon mekanizması EIS ve LPR ölçümlerinden hesaplanan yüzey kaplanma kesirleri ile belirlenmiştir. Şekil 5'te görüldüğü gibi, $C$ (derişim)'ye karşı grafiğe geçirilen $C / \theta$ (yüzey kaplama kesri) değişiminin doğrusal olması $\left(R^{2} \cong 1\right)$ PDSE'nin asidik çözeltide bakırın yüzeyine adsorpsiyonunun Langmuir adsorpsiyon izotermine uyduğunu göstermektedir. Eşitlik 4'te bu izotermi gösterilmektedir [28].

$$
\frac{C_{(i n h)}}{\theta}=\frac{1}{K_{(a d s)}}+C_{(i n h)}
$$

Eşitlik 4 yardımı ile izotermin kaymasından $K_{\text {ads }}$ değeri $0,984 \times 10^{3}$ olarak hesaplanmıştır. Hesaplanan $K_{\text {ads }}$ değerinin yüksek olması kullanılan PDSE inhibitörünün asidik ortamda bakır metal yüzeyine güçlü bir şekilde adsorbe olabileceğini göstermektedir [28].

Adsorpsiyon serbest enerjisi $\left(\Delta G^{\circ}{ }_{\text {ads }}\right)$ ise aşağıda verilen Eşitlik 5 yardımıyla hesaplanmıştır;

$\Delta G_{a d s}^{\circ}=-R T \ln \left(55,5 K_{a d s}\right)$ 


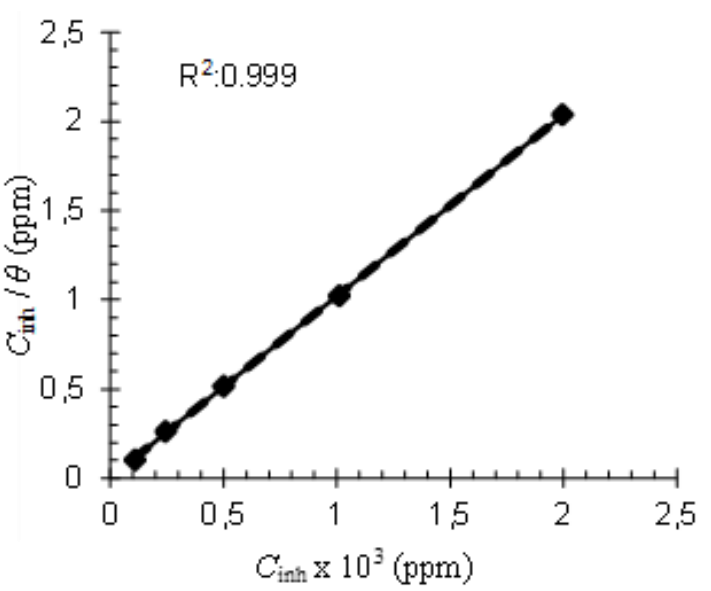

Şekil 5. Bakırın inhibitörlü ortamda elde edilen Langmuir adsorpsiyon izotermi

Eşitlik 5'ten, PDSE inhibitörünün $0.5 \mathrm{M} \mathrm{H}_{2} \mathrm{SO}_{4}$ içerisinde $\Delta G^{\circ}{ }_{\text {ads }}$ değeri $-27.025 \mathrm{~kJ} \mathrm{~mol}^{-1}$ olarak hesaplanmıştır. Negaitf $\Delta G^{\circ}$ ads değeri, inhibitörün metal yüzeyine adsorpsiyonunun kendiliğinden olduğunu göstermektedir. $\Delta G^{\circ}$ ads değerinin yüksek olması ise inhibitör molekülleri ve metal yüzeyi arasında güçlü etkileşimler ile açıklanabilir [27].

\subsubsection{Sıfır Yük Potansiyeli}

$E_{\mathrm{pzc}}$, organik bileşikler ve metaller arasındaki etkileşim türü hakkında önemli bilgiler verir [18]. $E_{\mathrm{r}}$, Antropov'un rasyonel korozyon potansiyeli olarak tanımlanır ve Eşitlik 6'da verilen formüle göre elde edilir [18],

$$
E_{r}=E_{o c p}-E_{p z c}
$$

Eşitlik 6'da $E_{\text {ocp }}$ açık devre potansiyeline, $E_{\mathrm{pzc}}$ ise sıfır yük potansiyeline karşılık gelmektedir. Şekil 6'da görüldüğü gibi, PDSE'nin asidik ortamdaki PZC eğrisinden $E_{\mathrm{pzc}}$ değeri,- $0,119 \mathrm{~V}$ olarak belirlenmiştir. $\mathrm{Bu}$ sonuca göre $E_{\mathrm{r}}$ değeri $0.021 \mathrm{~V}$ olarak belirlenmiştir. $\mathrm{Bu}$ değerin pozitif olması, metalin yüzey yükünün pozitif olduğunu göstermektedir. Dolayısıyla ile öncelikle negatif yüklü sülfat iyonları metal yüzeyine adsorplanarak yüzeyi negatif yüklemekte, sonrasında asidik ortamda protonlanmış (pozitif yüklü) inhibitör molekülleri sülfat iyonları üzerinden metal yüzeyine tutunarak koruyucu bir film oluşturmaktadır.

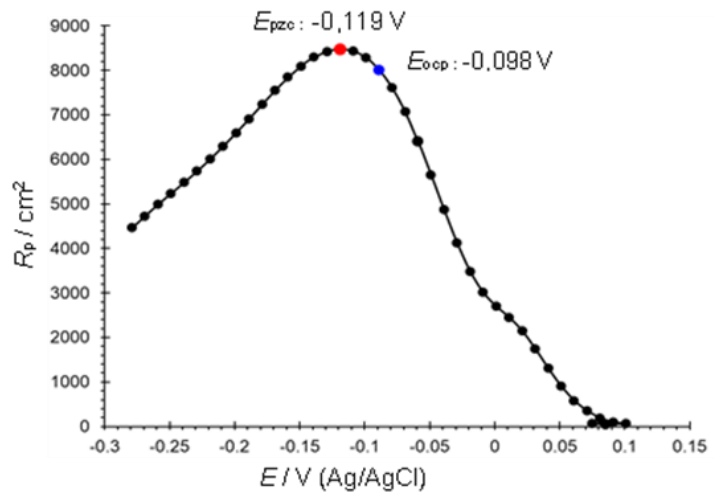

Şekil 6. Bakırın 2000 ppm PDSE içeren 0,5 $\mathrm{M} \mathrm{H}_{2} \mathrm{SO}_{4}$ çözeltisinde elde edilen PZC eğrisi

\section{SONUÇ}

Bakırın PDSE içeren 0,5 $\mathrm{M} \mathrm{H}_{2} \mathrm{SO}_{4}$ çözeltisindeki korozyon hızı, yüzey mekanizması ve metal/çözelti etkileşimlerini aydınlatmak için yapılan çalışmalardan aşağıda maddeler halinde verilen sonuçlar ortaya çıkarılmıştır;

1) PDSE' nin varlığının $0,5 \mathrm{M} \mathrm{H}_{2} \mathrm{SO}_{4}$ çözeltisinde bakırın korozyonunu yavaşlattığı belirlenmiştir.

2) LPR, EIS ve PP ölçümlerinden elde edilen sonuçlardan hesaplanan etkinlik değerinin artan derişimle artığı belirlenmiştir.

3) PDSE inhibitörünün asidik ortamdaki derişiminin artması ile bakırın korozyon potansiyelinin daha negatif potansiyellere kaydırdığ

4) PDSE inhibitörünün asidik ortamda bakır metali yüzeyine adsorpsiyonunun Langmuir adsorpsiyon izotermine uyduğu belirlenmiştir.

5) PZC çalışmaları, metalin yüzey yükünün pozitif olduğunu göstermiştir.

6) Temas açısı çalışmaları, yüzey yükünün hidrofobik olduğunu göstermiştir.

PDSE'nin, asidik çözeltide metal yüzeyinde koruyucu bir film oluşturarak bakırın korozyonunu önemli ölçüde yavaşlattığı belirlenmiştir. Düşük derişimlerde bile, yüksek etkinlik elde edilebileceğinden PDSE'nin doğal çevre dostu doğal bir atı olması gibi ekonomik faktörde dikkate alındığında PDSE'nin pratik uygulamalarda bakırın asidik çözeltide korozyonunu önlemek amacı ile inhibitör olarak kullanımı uygun olabilir.

\section{Teşekkür}

Bu çalışma, Bingöl Üniversitesi Bilimsel Araştırma Projeleri Koordinasyon Birimi (Proje Numaras: GMYO.2021.00.001) tarafindan finansal olarak desteklenmiştir. Bingöl Üniversitesi Bilimsel Araştırmalar ve Projeler Birimine, Bingöl Üniversitesi Merkezi Araştırma Laboratuvarına ve İş Sağlığı ve Güvenliği Bölümüne teşekkür ederiz. 


\section{KAYNAKLAR}

[1] Özgün Ö, Erçetin A. Microstructural and mechanical properties of $\mathrm{Cr}-\mathrm{C}$ reinforced $\mathrm{Cu}$ matrix composites produced through powder metallurgy method, $\operatorname{Tr} \mathrm{J}$ Nature Sci. 2017;6(2):1-6.

[2] Ercetin A, Aslantaş K. Production of $\mathrm{WCu}$ electrical contact material via conventional powder metallurgy method: Characterization, mechanical and electrical properties. Tr J Nature Sci. 2017;6(1):37-42.

[3] Şahin AE, Yumuşak çeliğin asidik ortamdaki korozyon davranışına 5-(4dimetilaminobenzyliden)-rodanin molekülünün etkisi. Mühendislik Bilimleri ve Tasarım Dergisi 2019;7:803-810.

[4] Solmaz R, Şahin AE, Geçibesler İH, Kardaş G. Investigation of the inhibition effect of cucurbita moschata pumpkin shell on mild steel corrosion, Physical Sciences, 2019;14(2):1-10

[5] Erbil M. Korozyon (İlkeler- Önlemler), Ankara, 2012.

[6] Erbil M. Demirin korozyonu üzerine bazı yeni inhibitörlerin etkinliklerinin araştırılması. Ankara Üniversitesi Doçentlik Tezi, Ankara,117s, 1980.

[7] Erbil M. Korozyon inhibitörleri ve inhibitör etkinliklerinin saptanması, Segem, Ankara, 14, 1984.

[8] Üneri S. Korozyon inhibitörlerinin prensipleri ve pratiği. Segem, Ankara,121, 1984 Üneri S., Korozyon ve Önlenmesi, SEGEM, Ankara1998.

[9] Solmaz R, Şahin AE, Döner A, Kardaş G. The investigation of synergistic inhibition effect of rhodanine and iodide ion on the corrosion of copper in sulphuric acid solution. Corrosion Science 2011;53:3231-3240.

[10] Solmaz R, Altunbaş E, Kardaş G. Investigation of adsorption and corrosion inhibition effect of 1,1'-thiocarbonyldiimidazole on mild steel in hydrochloric acid solution. Prot Met Phys Chem Surfaces. 2011;47(2):264-271.

[11] Liu L, Lu S, Wu YQ, Xie JY, Xing J. Corrosion inhibition behavior of four benzimidazole derivatives and benzotriazole on copper surface. Anti-Corrosion Methods Mater. 2020;67(6):565-575

[12] Ekilik V V, Berezhnaya AG, Svyataya MN. Acridine derivatives as inhibitors of copper dissolution. Russ J Appl Chem. 2001;74(9):1500-1505.

[13] Xiang Q, He J. Combining theoretical and experimental researches to insight the anticorrosion nature of Citrus reticulata leaves extract. J Mol Liq. 2021;325.

[14] Batah A, Anejjar A, Bammou L, Belkhaouda M, Salghi R. Effect of apricot almond oil as green inhibitor for steel corrosion in hydrochloric media. Portugaliae Electrochimica Acta. 2020;38:201-214.

[15] Khaburs'kyi YM, Corrosion Resistance properties of the extracts pf plants raw materials in solutions of hydrochloric acid, Materials Science, 2015;51:131-137.

[16] Ongun Yüce A. Asidik Çözeltide yumuşak çeliğin korozyonu üzerine yeşil inhibitör olarak morus nigra pendula yaprak ekstraktının inhibisyon etkisinin incelenmesi. Çukurova Üniversitesi Mühendislik-Mimarlık Fakültesi Derg. 2019;34:183-192.

[17] Zhang X, Li W, Yu G. Evaluation of Idesia polycarpa Maxim fruits extract as a natural green corrosion inhibitor for copper in $0.5 \mathrm{M}$ sulfuric acid solution. J Mol Liq. 2018;318: 114080

[18] Tan B, Xiang B, Zhang S, et al. Papaya leaves extract as a novel eco-friendly corrosion inhibitor for $\mathrm{Cu}$ in $\mathrm{H} 2 \mathrm{SO} 4$ medium. J Colloid Interface Sci. 2021;582:918-931.

[19] Rehan AA. Corrosion Control by water-soluble extracts fromleaves of economic plants. Mat.wiss. u. Werkstofftech.2003;34:232 - 237.

[20] Tan B, Xiang B, Zhang S, Qiang Y, L Xu, Chen $\mathrm{S}$, He J. Papaya leaves extract as a novel ecofriendly corrosion inhibitor for $\mathrm{Cu}$ in $\mathrm{H} 2 \mathrm{SO} 4$ medium. Journal of Colloid and Interface Science 2021;582:918-931.

[21] Şahin AE, Solmaz R, Geçibesler İH, Kardaş G. Adsorption Ability Stability And Corrosion İnhibition Mechanism of Phoenix Dactylifera Extrat on Mild Steel, Materials Research Express, 2020;7:1-11.

[22] Solmaz R, Altunbas E, Kardas G. Adsorption and corrosion inhibition effect of 2-((5mercapto-1,3,4-thiadiazol-2-ylimino)methyl) phenol Schiff base on mild steel, Mater. Chem. Phys.2011;125:796-801.

[23] Song SM, Park CE, Yun K, Hwang CS, Oh SY, Park JM. Journal of Adhesion Science and Technology, 1998;12:541-561.

[24] Zhang J, Li H. 2-(2-chlorophenyl)-1Hbenzimidazole as a new corrosion unhibitor for copper in sulfuric acid. Int. J. Electrochem. Sci., 2020;15:5362 - 5372 .

[25] Vengatesh G, Sundaravadivelu M. Combining theoretical and experimental researches to insight the anti-corrosion nature of Citrus reticulata leaves extra. Journal of Molecular Liquids 2021;325:115218.

[26] Shalabia K, El-Gammala OA, Abdallah YM. Adsorption and inhibition effect of tetraazatetradentate macrocycle ligand and its Ni (II), $\mathrm{Cu}$ (II) complexes on the corrosion of $\mathrm{Cu} 10 \mathrm{Ni}$ alloy in $3.5 \% \mathrm{NaCl}$ solutions. Colloids and Surfaces A 2021;609:125653.

[27] Solmaz R, Altunbaş Şahin E, Döner A, Kardaş $\mathrm{G}$, The Investigation Of synergistic mhibition effect of rhodanine and iodide ion on the corrosion of copper in sulphuric acid solution, Corrosion Science, 2011;53:3231-3240. 